\title{
Effect of sampling design on abundance estimates of benthic invertebrates in environmental monitoring studies
}

\author{
Henrique N. Cabral ${ }^{1, *}$, Alberto G. Murta ${ }^{2}$ \\ ${ }^{1}$ Instituto de Oceanografia and Departamento de Biologia Animal, Faculdade de Ciências da Universidade de Lisboa, \\ Campo Grande, 1749-016 Lisboa, Portugal \\ ${ }^{2}$ Departamento de Recursos Marinhos, INIAP-IPIMAR, Avenida de Brasília, 1449-006 Lisboa, Portugal
}

\begin{abstract}
Random, stratified, systematic and adaptative sampling designs were analyzed comparatively using data of benthic invertebrate abundance in the mudflats of the Tagus estuary. Intensive core sampling was performed in spring and summer of 1996, in an area of $4 \mathrm{~m}^{2}$. Estimates determined from sub-sets of samples chosen using the various designs were compared. The mean values of the density estimates obtained by the various sampling designs and sample sizes differed significantly, and the main variation trends also differed according to species. For species with low abundace, i.e. Polydora ciliata and Sphaeroma monodi, the estimates obtained by random sampling (RS), systematic sampling (SyS) and stratified sampling (SS) were similar to the real density value, while those that resulted from the adaptive sampling (AS) design tended to overestimate density in the majority of cases. A different pattern was obtained for the abundant species, i.e. Streblospio shrubsolii and Scrobicularia plana. For these species, the mean values of the estimates obtained by RS, SyS and SS were similar and presented a negligible bias, although their variances were usually high. AS designs produced strongly biased estimates, although with low variance. The mean values of these estimates were considerably lower than the true mean density value. Comparison of the mean variance estimates for the sample sizes considered for each sampling design with the RS variance estimates revealed that the lowest variance ratios were obtained with SS designs.
\end{abstract}

KEY WORDS: Sampling design - Sample size - Adaptive sampling • Benthic invertebrates • Environmental monitoring

\section{INTRODUCTION}

Several organisms have been used to investigate the health of aquatic systems and to assess environmental impacts (Attrill \& Depledge 1997). Benthic invertebrates are among the most common organisms used in biological monitoring, since this group generally reflects anthropogenic impacts (e.g. Rosenberg \& Resh 1993). Benthic fauna present some advantages in relation to other biological groups (e.g. plankton, fish and marine birds): (1) a high species richness with a variety of life history patterns and tolerances to habitat disturbance, including organic enrichment and contamination of sediments; (2) the majority of the species are sedentary; (3) their responses integrate water and sediment quality changes; (4) some species have relatively long life spans; and (5) they are key elements in the food web of aquatic systems and affect chemical fluxes between sediments and water columns through bioturbation and suspension feeding activities (Boesh \& Rosenberg 1981, Aller 1982, Dauer et al. 1982, Hartley 1982, Hargrave \& Theil 1983, Gray et al. 1988, Warwick et al. 1990, Weston, 1990, Weisberg et al. 1997).

Although benthic macroinvertebrate communities have many advantages as indicators, it is often partic- 
ularly difficult to distinguish between natural and anthropogenic changes. Benthic communities vary considerably according to environmental conditions (e.g. Boesch 1973, Chester et al. 1983, Flint \& Kalke 1985, McLusky 1989). Most benthic macroinvertebrates have a highly aggregated small-scale distribution induced by several environmental variables, such as substratum type, food availability and predation (Cummins 1962). In this context, the development of sampling strategies to estimate benthic organism abundance has long been a major concern in many studies, since estimates generally vary considerably according to the sampling design and effort (e.g. Statzner 1998).

The optimization of precision, accuracy and cost in relation to the objectives of the study is difficult to achieve (Statzner et al. 1998). A large variety of sampling strategies have been used, namely random, stratified, systematic and sequential designs (Jackson \& Resh 1988, Beisel et al. 1998, Statzner et al. 1998). Although some theoretical properties associated with these methods are known in depth, comparisons between their efficiencies in real case studies are scarce. The selection of a particular method may have marked implications on estimates. This is particularly relevant for the highly clumped distributions that benthic invertebrates generally present. More recently, adaptive sampling approaches have been proposed, which are especially suitable when contagious distribution patterns are found.

The aim of the present work was to assess the accuracy and precision of the estimates for mean density and variance of benthic invertebrates obtained with different sampling designs. Here, 3 random (simple, stratified and systematic) and 4 adaptive sampling strategies, at 4 levels of sampling effort, are compared.

\section{MATERIALS AND METHODS}

Sampling procedures. A census was made of the benthic macrofauna in a square area with a side of $2.25 \mathrm{~m}$. This area, located on an intertidal mudflat in the upper Tagus estuary, was divided into 225 small quadrats, the upper $20 \mathrm{~cm}$ of sediment in each quadrat being removed with a $0.15 \times 0.15 \mathrm{~m}$ square core sampler (the total area sampled was $5.0625 \mathrm{~m}^{2}$ ). The 225 pieces of sediment were separately washed through a $0.5 \mathrm{~mm}$ mesh sieve and the remains put in buffered formalin for later identification.

Data analysis. Dispersion indices were determined for each species in order to identify species with similar spatial distribution and abundance patterns. Two indices were calculated: one based on quadrat counts $\left(\mathrm{DI}_{\mathrm{A}}\right)$ (Krebs 1998), and one based on distance methods
$\left(\mathrm{DI}_{\mathrm{B}}\right)$ (Hines \& Hines 1979), given by the following expressions:

$$
\begin{gathered}
\mathrm{DI}_{\mathrm{A}}=\frac{s^{2}}{\bar{x}} \\
\mathrm{DI}_{\mathrm{B}}=\left(\frac{s}{\bar{x}}\right)^{2}+1
\end{gathered}
$$

where $\bar{x}$ and $s$ are, respectively, the mean and SD of the number of individuals over the 225 quadrats.

A cluster analysis was performed using the index values, occurrence frequency and mean density data. The Euclidean distance and the average linkage method were used to select a sub-set of species for further analysis.

Monte Carlo simulations were carried out for each sampling scheme:

(1) Random sampling (RS): $n$ elements of the 225 quadrats were randomly sampled;

(2) Stratified random sampling (SS): 4 strata of approximately equal size were defined, and $n$ quadrats from each stratum were sampled, allocating the sampling effort proportionally to the size of the strata;

(3) Systematic sampling (SyS) : 1 quadrat out of the 225 was randomly selected and, starting from that one, $n-1$ evenly spaced quadrats were sampled;

(4) Adaptive sampling (AS): $n$ quadrats out of the 225 were randomly selected, and whenever the number of individuals of the considered taxa in a quadrat was higher than a critical value (crit), the spatially contiguous quadrats were also selected. The procedure was repeated with all the newly sampled quadrats, until sample size reached $N$.

In the function simulating $\mathrm{AS}$, mean abundance $(\mu)$ was estimated according to the Horvitz-Thompson estimator, as proposed by Thompson (1992):

$$
\hat{\mu}=\frac{1}{N} \sum_{i=1}^{v} \frac{y_{i} J_{i}}{\pi_{i}^{\prime}}
$$

where $N$ is the total number of sampling units in the study area, $v$ is the number of networks identified in the first stage of sampling $n$ units, $y_{i}$ is the sample mean obtained for network $i, J_{i}$ is an indicator variable that is zero if the ith unit in the sample does not satisfy the selection criteria, otherwise $J_{i}=1$, and $\pi_{\mathrm{i}}^{\prime}$ is given by

$$
\pi_{i}=1-\frac{\left(\frac{N-m_{i}}{n}\right)}{\left(\frac{N}{n}\right)}
$$

where $N$ is as defined above, $n$ is the initial sample size at the first stage and $m_{i}$ is the number of sampling units in network $i$.

To compare the sampling procedures, abundance estimates were calculated from samples with 15, 20, 30 and 40 elements. For the adaptive sampling scheme, 
initial sample sizes of 5 and 10 were considered and 2 critical values were used (1 and 5). A higher number of AS designs were considered compared to the other methods, since the estimates obtained by adaptive designs are extremely dependent on the initial sample size and the selection criteria. It is therefore important to assess the influence of such criteria on the estimates. A total of 28 sampling procedures were compared in this study, each one being repeated 1000 times in the Monte Carlo procedure. The effects of sampling design and sampling size on bias were tested for each species by a 2-way ANOVA. Data (absolute difference between each estimate and the real value) was logtransformed to account for homoscedasticity. A 0.05 significance level was used in all test procedures.

\section{RESULTS}

A total of 15 macroinvertebrate species were identified in the survey area. The density and frequency estimates determined from the census of the ca. $5 \mathrm{~m}^{2}$ mudflat area differed considerably according to species (values between 1.58 and 246.52 ind. $\mathrm{m}^{-2}$ and between 3.6 and $84.4 \%$, respectively), as did the dispersion indices. Since one of the objectives was to study the performance of the sampling designs according to species abundance pattern, 4 species were chosen, one from each dendrogram cluster identified. This sub-set was intended to be representative of the major species abundance patterns identified in the study area. Considering the mean density as ind $\mathrm{m}^{-2}$ (D) and the frequency of occurrence (FO), the 4 chosen species represented the following patterns: (1) Polydora ciliata: low D and FO, (2) Sphaeroma monodi: moderate D and FO, (3) Streblospio shrubsolii: high D and moderate FO, and (4) Scrobicularia plana: high D and FO. These species showed a gradient in the dispersion values and frequency of occurrence varying from 0.96 ( $P$. ciliata) to 22.75 (S. shrubsolii) for $\mathrm{DI}_{\mathrm{A}}$, from 1.21 ( $P$. ciliata) to 7.56 (S. plana) for $\mathrm{DI}_{\mathrm{B}}$ and from 4.4 (P. ciliata) to $84.4 \%$ (S. plana).

The mean values of the density estimates obtained by the various sampling designs and sample sizes showed marked differences (Table 1). The factorial ANOVA for each species resulted in significant interactions at the $5 \%$ level between 'Sample size' and 'Sampling design' ( $F>3.79$, p $<0.05$, in all tests). The distributions of the density estimates obtained in the simulations are shown in Fig. 1. Differences between sampling designs and sample sizes are clearly visible, and also show variations between species.

Table 1. Mean density (ind. $\mathrm{m}^{-2}$ ) values and estimates obtained by simulations of the different sampling designs for each species, according to sample size (N) (SD and bias in brackets); RS: random sampling; SyS: Systematic sampling; SS: stratified sampling; AS5.1: Adaptive sampling with $n=5$ and crit $=1$; AS10.1: Adaptive sampling with $n=10$ and crit $=1$; Results obtained with AS5.5 and AS10.5 not shown, since they performed very poorly (see 'Materials and methods' for details)

\begin{tabular}{|lccccc|}
\hline Sampling design & $N$ & Polydora ciliata & Sphaeroma monodi & Streblospio shrubsolii & Scrobicularia plana \\
\hline RS & 15 & $2.01(2.26 ; 0.03)$ & $20.43(11.67 ; 0.08)$ & $131.72(91.05 ; 1.94)$ & $251.59(65.2 ; 5.07)$ \\
RS & 20 & $2.08(2.05 ; 0.10)$ & $20.44(10.31 ; 0.09)$ & $130.24(76.4 ; 0.46)$ & $243.08(53.74 ;-3.44)$ \\
RS & 30 & $1.95(1.55 ;-0.03)$ & $20.21(8.03 ;-0.14)$ & $128.92(58.89 ;-0.86)$ & $247.97(43.24 ; 1.45)$ \\
RS & 40 & $1.98(1.3 ; 0.00)$ & $20.14(6.7 ;-0.21)$ & $131.53(49.57 ; 1.75)$ & $247.46(36.79 ; 0.94)$ \\
SyS & 15 & $2.68(3.45 ; 0.70)$ & $22.12(10.66 ; 1.77)$ & $114.35(80.26 ;-15.43)$ & $239.42(65.52 ;-7.10)$ \\
SyS & 20 & $2.22(2.16 ; 0.24)$ & $22.45(11.34 ; 2.10)$ & $156.89(72.30 ; 27.11)$ & $243.9(45.22 ;-2.62)$ \\
SyS & 30 & $2.3(2.02 ; 0.32)$ & $19.77(10.96 ;-0.58)$ & $131.71(57.04 ; 1.93)$ & $261.55(74.38 ; 15.03)$ \\
SyS & 40 & $2.24(0.91 ; 0.26)$ & $20.35(8.64 ; 0.00)$ & $128.55(54.32 ;-1.23)$ & $257.45(54.28 ; 10.93)$ \\
SS & 15 & $2.08(2.35 ; 0.10)$ & $21.08(11.56 ; 0.73)$ & $125.88(81.89 ;-3.90)$ & $244.17(57.45 ;-2.35)$ \\
SS & 20 & $2.14(2.11 ; 0.16)$ & $21.2(10.20 ; 0.85)$ & $130.98(74.25 ; 1.20)$ & $244.85(51.34 ;-1.67)$ \\
SS & 30 & $2.07(1.56 ; 0.09)$ & $21.11(8.16 ; 0.76)$ & $131.21(57.02 ; 1.43)$ & $245.69(39.65 ;-0.83)$ \\
SS & 40 & $1.92(1.25 ;-0.06)$ & $20.78(6.69 ; 0.43)$ & $128.44(50.22 ;-1.34)$ & $246.01(35.95 ;-0.51)$ \\
AS10.1 & 15 & $2.11(4.2 ; 0.13)$ & $68.66(30.87 ; 48.31)$ & $14.98(10.32 ;-114.8)$ & $106.22(78.83 ;-140.30)$ \\
AS10.1 & 20 & $2.01(4.16 ; 0.03)$ & $69.95(27.91 ; 49.60)$ & $16.16(12.79 ;-113.62)$ & $108.31(75.43 ;-138.21)$ \\
AS10.1 & 30 & $1.75(3.9 ;-0.23)$ & $77.2(23.12 ; 56.85)$ & $17.84(13.66 ;-111.94)$ & $109.67(71.67 ;-136.85)$ \\
AS10.1 & 40 & $1.76(3.9 ;-0.22)$ & $85.37(20.09 ; 65.02)$ & $19.34(15.13 ;-110.44)$ & $115.27(87.15 ;-131.25)$ \\
AS5.1 & 15 & $1.89(2.71 ;-0.09)$ & $38.28(18.46 ; 17.93)$ & $10.38(4.21 ;-119.4)$ & $70.65(39.18 ;-175.87)$ \\
AS5.1 & 20 & $1.93(2.85 ;-0.05)$ & $42.35(17.21 ; 22)$ & $11.80(5.56 ;-117.98)$ & $76.79(37.01 ;-169.73)$ \\
AS5.1 & 30 & $1.86(2.70 ;-0.12)$ & $49.75(15.32 ; 29.4)$ & $14.83(6.87 ;-114.95)$ & $83.73(31.49 ;-162.79)$ \\
AS5.1 & 40 & $2.02(2.83 ; 0.04)$ & $58.77(14.55 ; 38.42)$ & $17.19(7.65 ;-112.59)$ & $90.13(37.84 ;-156.39)$ \\
Mean density values ${ }^{\mathrm{a}}$ & & & & & \\
& & & & &
\end{tabular}


For Polydora ciliata, the mean values of the density estimates obtained by RS, SyS, SS and AS with selection criteria equal to 1 (AS1) were similar to the real value of 1.98 ind. $\mathrm{m}^{-2}$. Those from the AS design with selection criteria equal to 5 (AS5) differed considerably. As Fig. 1 shows, the estimate distribution obtained for the AS1 design is extremely biased, with a median close to that obtained for AS5.

Similar results were obtained for Sphaeroma monodi, the lowest variance and bias estimates being those obtained by RS, SyS and SS. Unlike the results obtained for Polydora ciliata, the estimates from AS designs tended to overestimate density, particularly when the selection criterion of 5 was used. The variance of these estimates was also considerably higher than those from the other sampling methods (Table 1, Fig. 1).

A different pattern was registered for the abundant species, i.e. Streblospio shrubsolii and Scrobicularia plana. For these species, the mean values of the estimates obtained by RS, SyS and SS were similar and presented a negligible bias, although their variances were high. AS designs produced strongly biased estimates, although with low variance. The mean estimates were considerably lower than the true mean density value (especially when the selection criterion used was 5) (Table 1, Fig. 1). Some of the variance estimates obtained for $S$. plana with AS designs were higher than those obtained with the other sampling schemes, which was not the case for the S. shrubsollii data set.

Comparison of the mean variance estimates for the sample sizes considered for each sampling design with the RS variance estimates reveals that the lowest variance ratios were obtained with SS (Table 2). SyS also presented values lower than 2, while AS methods had high variance ratios (generally above 2) (Table 2).
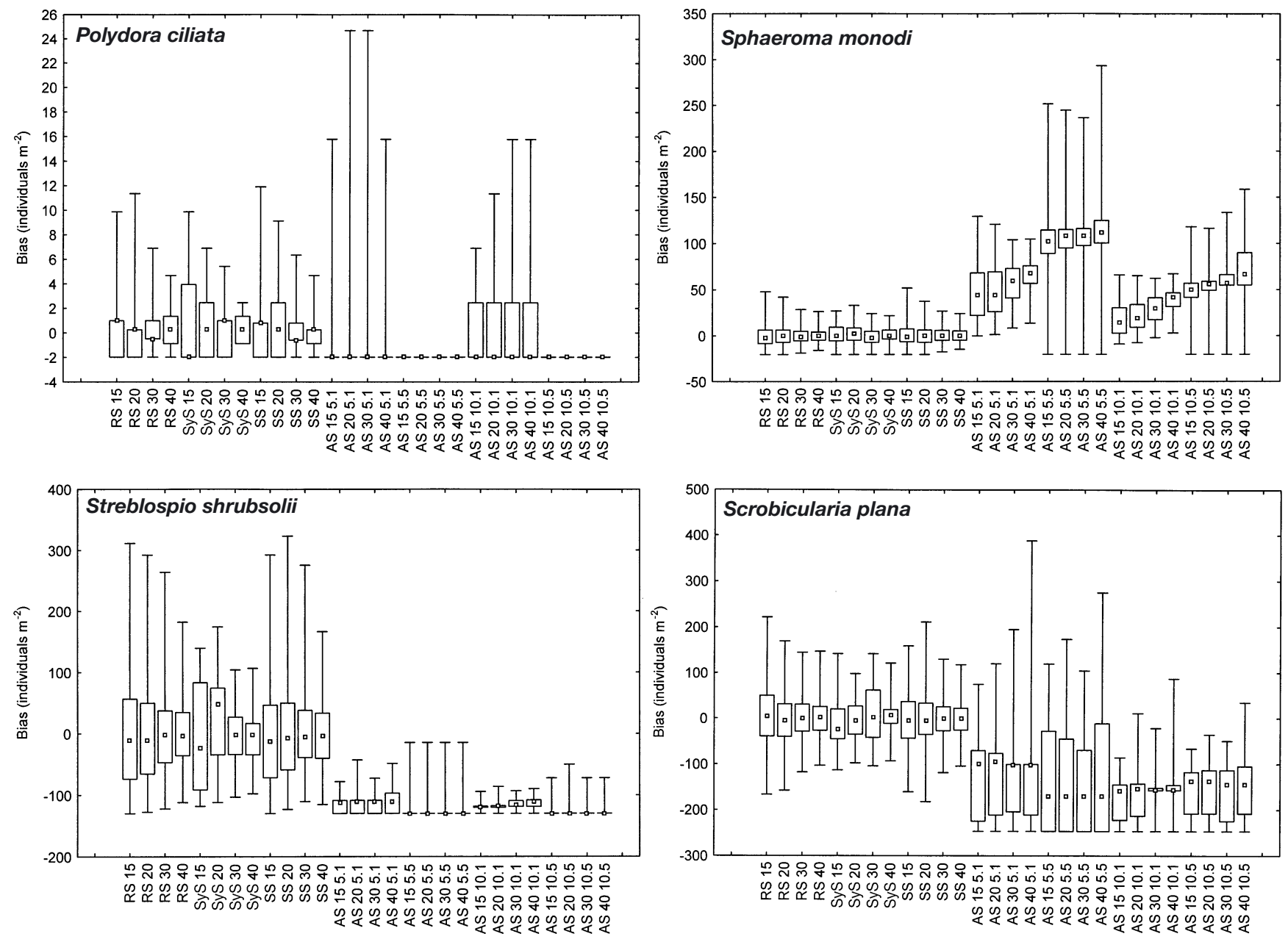

Fig. 1. Polydora ciliata, Sphaeroma monodi, Streblospiio shrubsolii and Scrobicularia plana. Bias of density estimates obtained by simulating different sampling designs and sample sizes (middle square: median; box: $25 \%$ and $75 \%$ percentiles, whiskers: minimum and maximum). RS: random sampling; SyS: systematic sampling; SS: stratified random sampling; AS: adaptive sampling 


\section{DISCUSSION}

The sampling method has a considerable impact on abundance estimates, and the development of sampling designs to obtain density estimates of macroinvertebrate populations has long been a major concern in benthic ecology studies (Statzner et al. 1998). Sampling design should optimize precision, accuracy and cost, which is generally difficult to achieve. To a large extent, this difficulty lies in the contagious spatial distributions of most benthos populations. If a common random sampling design is applied in this context, the sample size required to obtain a conventional standard (e.g. $95 \%$ confidence limits for ca. $40 \%$ error) for population estimate is extremely high (Elliott 1977, Resh 1979, Norris et al. 1992, Statzner et al. 1998). To overcome these problems several alternative sampling methods have been developed, in particular the adaptive sampling design introduced by Thompson (1990), which is expected to produce more precise and low variance population estimates whenever individuals are spatially clustered.

Besides the theoretical properties of estimators, the practical aspects related to the application of sampling designs should also be considered. Among the schemes considered in the present study, the implications for the sampling process are considerably more complex in the case of adaptive sampling. Generally, adaptive sampling requires, among others, that (1) the individuals of the target population(s) can be identified rapidly, (2) the spatial distribution of individuals is sufficiently patchy to be worth the extra effort of adaptive sampling, and (3) selection of a suitable critical value (Lo et al. 1997). These requirements are difficult to meet in studies on benthic invertebrates, especially with regard to the effort needed for the identification of organisms and the acquisition of extra samples.

The results obtained in the present study show that random, systematic and stratified sampling designs tend to produce more precise density estimates than adaptive sampling, although, for some cases, the vari-

Table 2. Mean values of variance ratios in relation to random sampling (RS) variance estimates. SyS: systematic sampling; SS: stratified random sampling; AS: adaptive sampling

\begin{tabular}{|lcccc|}
\hline $\begin{array}{l}\text { Sampling } \\
\text { design }\end{array}$ & $\begin{array}{c}\text { Polydora } \\
\text { ciliata }\end{array}$ & $\begin{array}{c}\text { Sphaeroma } \\
\text { monodi }\end{array}$ & $\begin{array}{c}\text { Streblospio } \\
\text { shrubsolii }\end{array}$ & $\begin{array}{c}\text { Scrobicularia } \\
\text { plana }\end{array}$ \\
\hline SyS & 1.4 & 1.4 & 1.0 & 1.7 \\
SS & 1.0 & 1.0 & 0.9 & 0.9 \\
AS10.1 & 5.7 & 7.9 & 0.0 & 2.9 \\
AS10.5 & 0.0 & 32.5 & 0.1 & 6.3 \\
AS5.1 & 2.8 & 3.4 & 0.0 & 0.6 \\
AS5.5 & 0.0 & 4.9 & 0.0 & 1.9 \\
\hline
\end{tabular}

ance of the estimates was considerably high. Also, the performance of the sampling designs differed according to the species abundance and spatial pattern of occurrence, which emphasizes the importance of some key aspects of adaptive schemes, namely the critical value and the patch distribution and size.

The impact of the critical value in abundance and variance estimates has been discussed by several authors. Lo et al. (1997), in a study of Pacific hake larval abundance, concluded that the variance estimates are considerably lower when the critical value is set at a higher level. It has been suggested that a large critical value would increase the precision of an estimate (e.g. Lo et al. 1997), but according Lo et al. (1997) this is only true as long as the value is not so high that it substantially reduces the chance of sampling patches. This was seen with Polydora ciliata in the present study, when the critical value of 5 was used. The estimates were strongly biased (far below the real mean value) and the variance was negligible, since almost no sampling units presented such a high value of individuals. Some authors have suggested alternative criteria for the selection of a critical value. Thompson \& Seber (1996) developed a method based on order statistics, according to which the neighboring units of the initial site are sampled in cases where observations produce values higher than a determined percentile. However, as outlined by Lo et al. (1997), this procedure may not be practical for marine surveys. Patch size and distribution have also been recognized as critical factors affecting estimation under adaptive sampling designs (e.g Lo et al. 1997), but few studies have focused on this topic.

The variance ratios show that the estimates obtained from stratified designs were similar to those from random designs. This result may be due to the homogeneity of the surveyed area. If the study had also considered areas with different sediment compositions or subjected to different environmental conditions, stratified designs would be expected to produce estimates with higher precision and lower variance than random sampling (e.g. Thompson 1992). Stratified designs have almost the same cost and difficulty as a random sampling scheme, although it is valuable to develop a pilot sampling survey in order to define strata and the optimal sample size allocation (Krebs 1998).

Selection of the best sampling method is extremely dependent on the particular case under analysis, and some authors point out that benthic macroinvertebrate sampling should be optimized using a flexible stategy. Statzner et al. (1998) have developed a 
particular method (the joint preference factor method) and demonstrated its efficacy. Nonetheless, the development of such particular methods could constrain the comparison of results obtained in studies with different sampling approaches.

Although adaptive sampling may improve the precision of density estimates in certain cases of highly aggregated spatial patterns, this sampling scheme produced extremely biased estimates in the present study. Further studies based on simulation of patch distribution and size are of extreme importance in order to evaluate in which conditions adaptive designs produce better estimates than random sampling methods.

Acknowledgements. The authors are grateful to Fundação para a Ciência e para a Tecnologia for funding.

\section{LITERATURE CITED}

Aller RC (1982) The effects of macrobenthos on chemical properties of marine sediments and overlying water. In: McCall PL, Tevesz MJS (eds) Animal-sediment relations. Plenum Press, New York, p 53-102

Attrill MJ, Depledge MH (1997) Community and population indicators of ecosystem health: targeting links between levels of biological organisation. Aquat Toxicol 38: 183-197

Beisel JN, Usseglio-Polatera P, Thomas S, Moreteau JC (1998) Influence de l'échantillonnage des communautés macrobenthiques sur l'évaluation de la qualité biologique d'un cours d'eau. Ann Limnol 34:445-454

Boesch DF (1973) Classification and community structure of macrobenthos in the Hampton Roads area, Virginia. Mar Biol 21:226-244

Boesh DF, Rosenberg R (1981) Response to stress in marine benthic communities. In: Barrett GW, Rosenberg R (eds) Stress effects on natural ecosystems. John Wiley, London, p 179-200

Chester AJ, Ferguson RL, Thayer GG (1983) Environmental gradients and benthic macroinvertebrate distributions in a shallow North Carolina estuary. Bull Mar Sci 33:282-295

Cummins KW (1962) An evaluation of some techniques for the collection and analysis of benthic samples with special emphasis on lotic waters. Am Midl Nat 67:477-504

Dauer DM, Rodi AJ Jr, Ranasinghe JA (1982) Effects of low dissolved oxygen events on the macrobenthos of the lower Chesapeake Bay (1985-1991). Mar Poll Bull 30:840-850

Elliott JM (1977) Some methods for the statistical analysis of samples of benthic invertebrates. Freshw Biol Assoc Sci Pub 25

Flint RW, Kalke RD (1985) Benthos structure and function in a south Texas estuary. Contrib Mar Sci 28:33-53
Gray JS, Ascan M, Carr MR, Clarke KR, Green RH, Pearson TH, Rosenberg R, Warwick RM (1988) Analysis of community attributes of the benthic macrofauna of Frierfjord/Langessundfjord and in a mesocosm experiment. Mar Ecol Prog Ser 46:151-165

Hargrave BT, Theil H (1983) Assessment of pollution-induced changes in benthic community structure. Mar Poll Bull 14: 41-46

Hartley JP (1982) Methods for monitoring offshore macrobenthos. Mar Poll Bull 13:150-154

Hines WGS, Hines RJ (1979) The Eberhardt statistic and the detection of nonrandomness of spatial point distributions. Biometrika 66:73-79

Jackson JK, Resh VH (1988) Sequential decision plans in monitoring benthic macroinvertebrates: cost savings, classification accuracy, and development of plans. Can J Fish Aquat Sci 45:280-286

Krebs CJ (1998) Ecological methodology. 2nd edn. Addison Wesley Longman, Menlo Park, CA

Lo NCH, Griffith D, Hunter JR (1997) Using a restricted adaptive cluster sampling to estimate Pacific hake larval abundance. Calif Coop Ocean Fish Invest Rep 38:103-112

McLusky DS (1989) The estuarine ecosystem. 2nd edn. Chapman \& Hall, London

Norris RH, McElravy EP, Resh VH (1992) The sampling problem. In: Calow P, Petts GE (eds) The rivers handbook. Blackwell, Oxford, p 282-306

Resh VH (1979) Sampling variability and life history features: basic considerations and the design of aquatic insect studies. J Fish Res Board Can 36:290-311

Rosenberg DM, Resh VH (1993) Introduction to freshwater biomonitoring and benthic macroinvertebrates. In: Rosenberg DM, Resh VH (eds) Freshwater biomonitoring and benthic macroinvertebrates. Chapman \& Hall, New York, p 1-9

Statzner B, Gore JA, Resh VH (1998) Monte Carlo simulations of benthic macroinvertebrate populations: estimates using random, stratified, and gradient sampling. J N Am Benthol Soc 17:324-337

Thompson SK (1990) Adaptive cluster sampling. J Am Stat Assoc 85:1050-1059

Thompson SK (1992) Sampling. Wiley, New York

Thompson SK, Seber GAF (1996) Adaptive sampling. Wiley, New York

Warwick RH, Platt HM, Clarke KR, Agard J, Gobin J (1990) Analysis of macrobenthic and meiobenthic community structure in relation to pollution and disturbance in Hamilton Harbor, Bermuda. J Exp Mar Biol Ecol 138: $119-142$

Weisberg SB, Ranasinghe JA, Dauer DM, Schaffner LC, Diaz RJ, Frithsen JB (1997) An estuarine benthic index of biotic integrity (B-IBI) for Chesapeake Bay. Estuaries 20: 149-158

Weston DP (1990) Quantitative examination of macrobenthic community changes along an organic enrichment gradient. Mar Ecol Prog Ser 61:233-244

Submitted: October 16, 2003; Accepted: May 4, 2004

Proofs received from author(s): July 13, 2004
Editorial responsibility: Otto Kinne (Editor), Oldendorf/Luhe, Germany

\author{
Proofs received from author(s): July 13, 2004
}

